\title{
Antioxidant an Antimicrobial Activities of the Leaf Extract of Salvia palaestina
}

\author{
Reem Sabbobeh $^{1,2}$, Hatem Hejaz ${ }^{1}$, Ali Jahajha ${ }^{3}$, Suha Al-Akhras ${ }^{3}$, Hashem Al-Jaas ${ }^{3}$, Saleh Abu-Lafi ${ }^{1, *}$ \\ ${ }^{1}$ Faculty of Pharmacy, Al-Quds University, P. O. Box 20002, Jerusalem, Palestine. ${ }^{2}$ Quality Control Department, General Directorate of Pharmacy, Ministry \\ of Health, Palestine. ${ }^{3}$ Central Public Health Laboratory, Ministry of Health, Ramallah, Palestine.
}

\begin{tabular}{|c|c|}
\hline ARTICLE INFO & ABSTRACT \\
\hline Article history: & \multirow{10}{*}{$\begin{array}{l}\text { Salvia palaestina (Lamiaceae) is listed as native plant in Flora palaestina. In the Palestinian kitchen, its leaves is } \\
\text { virtually used in daily basis with the breakfast tea to add its distinct pleasant flavor and aromatic aroma. In order } \\
\text { to investigate the antioxidant and antimicrobial potential of cultivated S. palaestina, the leaves of the herb were } \\
\text { collected, air-dried, steam distilled and the culminated essential oils were subjected to GC-MS analysis. About } \\
\text { two dozens of volatile and semivolatile phytochemicals were separated and identified. The principal components } \\
\text { were eucalyptol }(47.09 \% \text { ) and camphor }(8.73 \% \text { ). The antioxidant activity of the oil was estimated by } 2,2 \text { '- } \\
\text { diphenyl-1-picrylhydrazyl (DPPH) method. The IC } 50 \text { was } 2.333 \mathrm{mg} / \mathrm{ml} \text { after } 30 \mathrm{~min} \text {, while after } 90 \text { min it was } \\
1.585 \mathrm{mg} / \mathrm{ml} \text {, meaning that the antioxidant activity of the oil increased with time. Linear relation between } \\
\text { concentration and activity was observed. The antimicrobial activity was examined by the disc diffusion method. } \\
\text { The antimicrobial activity of } 5 \mu \text { l of the essential oil was found to be greater than the activity of gentamicin in the } \\
\text { case of Staphylococcus aureus while it was nearly the same as gentamicin against E. coli. Furthermore, this } \\
\text { concentration was two times more active than nystatin against Candida albicans. }\end{array}$} \\
\hline$/ 10 / 2015$ & \\
\hline Revi & \\
\hline Acce & \\
\hline Available online: $26 / 01 / 2016$ & \\
\hline Key words: & \\
\hline Antioxidant, DPPH, & \\
\hline Antimicrobial Salvia & \\
\hline & \\
\hline GC-MS. & \\
\hline
\end{tabular}

\section{INTRODUCTION}

Infectious diseases represent a significant cause of morbidity and mortality worldwide and the developing countries in particular (Enwonwu and Salako, 2000). Consequently, pharmaceutical companies were motivated to develop new antimicrobial drugs because of the emergence of microorganisms resistant to available antimicrobials. It is obvious that bacterial species have the genetic ability to develop and transmit resistance against currently existing antimicrobials. This can be witnessed from the frequent reports on the isolation of bacteria that became multi-resistant to available antimicrobials at the recommended therapeutic dose. Thus, recently, natural products with antimicrobial activity have gained more attention due to safety concerns and to increasing resistance to available antibiotics (Palombo and Semple, 2002). Developments in biomedical science emphasize the involvement of free radicals in the pathophysiology of many diseases, particularly, degenerative diseases.

\footnotetext{
* Corresponding Author

Prof. Saleh Abu-Lafi, Faculty of Pharmacy, Al-Quds University, P.O. Box 20002, Abu-Dies, Palestine. Tel. and Fax: + 970-2-2790413

Email: sabulafi@science.alquds.edu
}

They can occur as a consequence of cellular damage by free radicals, which are produced either from normal cell metabolisms or from external sources including pollution, cigarette smoking, radiation and medication, etc. (Devasagayam et al., 2004). Free radicals are generally reactive oxygen species (ROS) and reactive nitrogen species (RNS). Both have toxic and beneficial effects and eventually balance is vital to achieve good health. Low or moderate levels of both, ROS and RNS, have positive impact on cellular responses and immune function. At high levels, oxidative stress is generated, which can damage cell structures and have great effect on developing chronic and degenerative conditions such as cancer, arthritis, aging, autoimmune disorders, cardiovascular and neurodegenerative diseases (Emerit and Michelson, 1982, Gutteridge and Halliwell, 1992, Valko et al., 2006, Halliwell, 2001, Liao and Yin, 2000).

Thus, antioxidants may play an important role in disease prevention and they are defined as compounds that inhibit or delay the oxidation of other molecules by inhibiting the initiation or propagation of oxidizing chain reactions. Their antioxidant activity is based on their ability to donate hydrogen atoms to free radicals and they are usually phenolic compounds with potent scavenging activity (Aruoma, 1994). 
Antioxidants are not only important in in medical field but are equally important in the food industry, which is evident in the increasing number of researches involving plants and food antioxidants (Bohm et al., 1998, Sanches-Silva et al., 2014). The beneficial medicinal effects of plants resulted mostly from secondary metabolites such as alkaloids, tannins, and polyphenolic compounds, which are synthesized and localized in certain parts in the plant (Stary, 1996). It was believed that these secondary metabolites might exert their action by resembling endogenous metabolites, hormones, ligands, signal transduction molecules or neurotransmitters (Briskin, 2000). As with other members of Lamiaceae family, Salvia species were reported to possess antimicrobial activity especially due to the presence of linalool and eucalyptol active ingredients (Sonboli et al., 2006). The commonly synthetic chemicals used as antioxidants such as butylated hydroxyanisole (BHA) and butylated hydroxytolune (BHT) have possible toxicity, which limit their use (Papas, 1999). Thus, natural antioxidants are highly demanded due to safety concerns (Lobo et al., 2010). For example, the essential oil of Salvia species is used in some countries as antioxidant due to its scavenging activity of free radicals to prevent and repair related degenerative diseases (Miguel, 2011). The antimicrobial activity of Salvia's essential oils was pronounced against Gram-positive more than Gram-negative bacteria (Sonboli et al., 2006, Miguel, et al., 2011, Fraternale et al., 2012, Kamatou et al., 2008). Salvia (Lamiaceae) is traditionally acknowledged in the Mediterranean region for its pharmacological benefits. S. palaestina (Meramia Falastinia in Arabic) is listed as native plant in Flora Palaestina. In the Palestinian kitchen, S. palaestina is virtually used in daily basis with the breakfast tea to add its distinct pleasant flavor and aromatic aroma. To the best of our knowledge, there has never been reported information about the antioxidant or antibacterial activities of the essential oil from cultivated $S$. palaestina (Lamiaceae) leaves growing in Palestine. The current study therefore is conducted to separate and identify the chemical composition and to assess the antioxidant and antibacterial potential of the essential oil of $S$. palaestina and to use the gas chromatography combined with mass spectrometry (GC-MS) in the electron impact mode to reveal the components identities.

\section{MATERIALS AND METHODS}

\section{Reagents}

GC grade n-hexane solvent and anhydrous sodium sulfate salt were purchased from Sigma-Aldrich Inc. (USA). Kovats retention index $(\mathrm{KI})$ reagent that consist of alkane standard mixture were between $\mathrm{C}_{10}-\mathrm{C}_{40}$ (even numbered) were purchased from Fluka, Switzerland. All the reference standards used in the research were kindly supplied by the Central Public Health Laboratory, Ministry of Health, Ramallah, Palestine.

\section{Plant materials}

Cultivated $S$. palaestina leaves were collected from Ya'bad, Jenin in the northern part of Palestine in May 2013. The plant species is properly authenticated by Prof. Khalid Sawalha, the director of the biodiversity research laboratory, Al-Quds University. Leaves were air dried in the absence of light at room temperature for a about one week untill constant weight is achieved.

\section{Instrumentation}

Essential oils were analyzed using Perkin Elmer, Clarus Gas Chromatography connected to Clarus $600 \mathrm{C}$ mass spectrometer (USA). The GC-MS was operated in the electron impact ionization mode (EI) at $70 \mathrm{eV}$. Perkin Elmer autosampler was used with $2 \mathrm{ml}$ vials. The GC is equipped with a fused silica capillary column; DB-5 MS consisted of (5\% diphenyl polysiloxane, $95 \%$ dimethyl polysiloxane) $28 \mathrm{~m} \mathrm{x} 0.25 \mathrm{~mm}$, coating film thickness is $0.25 \mu \mathrm{m}$ (Restck, USA).

\section{GC-MS chromatographic conditions}

Perkin Elmer GC-MS at electron impact mode (EI) was used. The flow rate of the carrier gas was $1 \mathrm{ml} \mathrm{He} / \mathrm{min}$. Injector temperature was set at $235^{\circ} \mathrm{C}$, the source temperature was at $250^{\circ} \mathrm{C}$ and the interface temperature was at $260^{\circ} \mathrm{C}$. Split ratio of 1:20 was adopted during the entire analysis. The column gradient temperature was held at $50^{\circ} \mathrm{C}$ for 2 minutes, then raised from $50^{\circ} \mathrm{C}$ to $180^{\circ} \mathrm{C}$ at a ramp of $5^{\circ} \mathrm{C} / \mathrm{min}$ and from $180^{\circ}$ to $280^{\circ} \mathrm{C}$ at a ramp rate of $15^{\circ} \mathrm{C} / \mathrm{min}$ and held there for extra $5 \mathrm{~min}$. Solvent cut time of 4.5 minutes was used to eliminate the solvent gigantic peak. The mass range was from $\mathrm{m} / \mathrm{z} 50$ to $480 \mathrm{Da}$, and of scan interval of 0.2 seconds. The obtained mass spectra were interpreted by comparing with the Mass Spectral Library of the National Institute of Standards and Technology (NIST).

\section{Steam distillation of Essential oils}

The essential oils of the $S$. palaestina leaves were isolated by steam distillation using Clevenger type apparatus for three hours: The water distillate was extracted twice with $100 \mathrm{ml}$ hexane. The hexane fractions were combined and dried over anhydrous sodium sulfate. Then, $300 \mu \mathrm{L}$ of hexane extract was diluted to $1 \mathrm{ml}$ with hexane and $1 \mu \mathrm{L}$ of the resulted diluted sample was injected to GC-MS using optimized method. The oil was obtained by evaporation of the hexane by rotary evaporator.

\section{Antioxidant activity}

Electrons donation ability of $S$. palaestina essential oils was measured from the bleaching of purple colored methanol solution of 2, 2'-diphenyl-1-picrylhydrazyl stable radical (DPPH) using spectrophotometric assay. After incubation period, the absorbance was measured at $517 \mathrm{~nm}$. Different concentrations of S. palaestina essential oil in methanol were prepared, 50 microliters of each concentration were added to $2 \mathrm{ml}$ of DPPH solution (DPPH concentration was $6 \times 10^{-5} \mathrm{M}$ ), final concentrations ranging from 0.122 to $1.35 \mathrm{mg} / \mathrm{ml}$ all samples were warped with aluminum foil and kept in dark place (drawer). Absorbance at wavelength $517 \mathrm{~nm}$ was measured at three different time points, 
namely after $30 \mathrm{~min}, 1$ hour and 1.5 hour. Percentage of the antioxidant scavenging activity $\left(\mathrm{A}_{\mathrm{i}} \%\right)$ was calculated from the following equation and then plotted against concentration to calculate the $\mathrm{A}_{\mathrm{i}} \%$ (Brand-Williams et al., 1995).

$\left(A_{i} \%\right)$, DPPH radical scavenging activity $\%=\left[1-\left(\frac{A s}{A c}\right)\right] \times 100 \%$

where, $A_{i}$ is the antioxidant index, As is the sample absorbance, Ac is the control absorbance. The control used was DPPH while the blank was methanol. $\mathrm{IC}_{50}$ (inhibitory concentration), which is defined as the concentration of sample required to inhibit the formation of DPPH radicals by $50 \%$ was calculated. Tert-butyl-4hydroxy toluene (BHT) was used as positive control, series of concentrations were prepared, and $5 \mu \mathrm{L}$ of each concentration was taken and to $2 \mathrm{ml}$ of DPPH was added as in S. palaestina essential oils, final concentrations for BHT ranged from 0.015 to 0.125 $\mathrm{mg} / \mathrm{ml}$.

\section{Antimicrobial activity \\ Reagents}

Nutrient agar (Difco), sabouraud dextrose agar (Difco) for Candida albicans, $0.9 \%$ sodium chloride AR solution, ciprofloxacin standard, gentamicin standard, nystatin standard, barium chloride AR and sulfuric acid AR were kindly supplied by the Central Public Health Laboratory, Ministry of Health, Ramallah, Palestine.

\section{Microbial strains}

The essential oil antimicrobial activity was evaluated against a panel of American Type Culture collection micro organisms, including the following strains; Staphylococcus aureus (ATCC\#25923), Staphylococcus epidermidis (ATCC\#12228), Candida albicans (ATCC\#10231), E.coli (ATCC\#8739) and Salmonella Typhimurium (ATCC\#14028). All these strains were from Becton Dickinson, France.

\section{Procedure}

The test was carried out using disk diffusion method. $5 \mu 1$ of (100\%) S. palaestina essential oil/positive control was added to each disk. Four disks were spread on the surface of the media in each plate. Plates were incubated at $37{ }^{\circ} \mathrm{C}$ for 24 hours in case of bacteria while for Candida albicans it was incubated at $25{ }^{\circ} \mathrm{C}$ for 72 hours. Then, zones of inhibition were measured and the results were documented. Solutions of gentamicin, ciprofloxacin and nystatin $(10 \mu \mathrm{g} / \mathrm{ml})$ were prepared and were used as positive control. The final concentration of both bacteria and fungi on each plate was about $1.5 \times 10^{6} \mathrm{CFU} / \mathrm{ml}$.

\section{RESULT AND DISCUSSION}

Twenty components were identified by GC-MS analysis. Figure 1 represents the total ion chromatogram (TIC) from GCMS, while figure 2 represents the detected components of $S$. palaestina and their abundance. The abundant components were the oxygenated monoterpenoid eucalyptol (47.09\%) and camphor $(8.73 \%)$. Other components that were present but to a lesser extent include $\beta$-caryophyllene $(2.88 \%), \alpha$-terpineol $(2.16 \%), \beta$-thujene $(1.77 \%)$ and epiglobulol $(1.25 \%)$. All the compounds were identified by matching their MS spectra with NIST MS spectral library database and by calculating their corresponding Kovats indices (KIs) and comparing them with those reported in the literature using the same DB-5 capillary column.

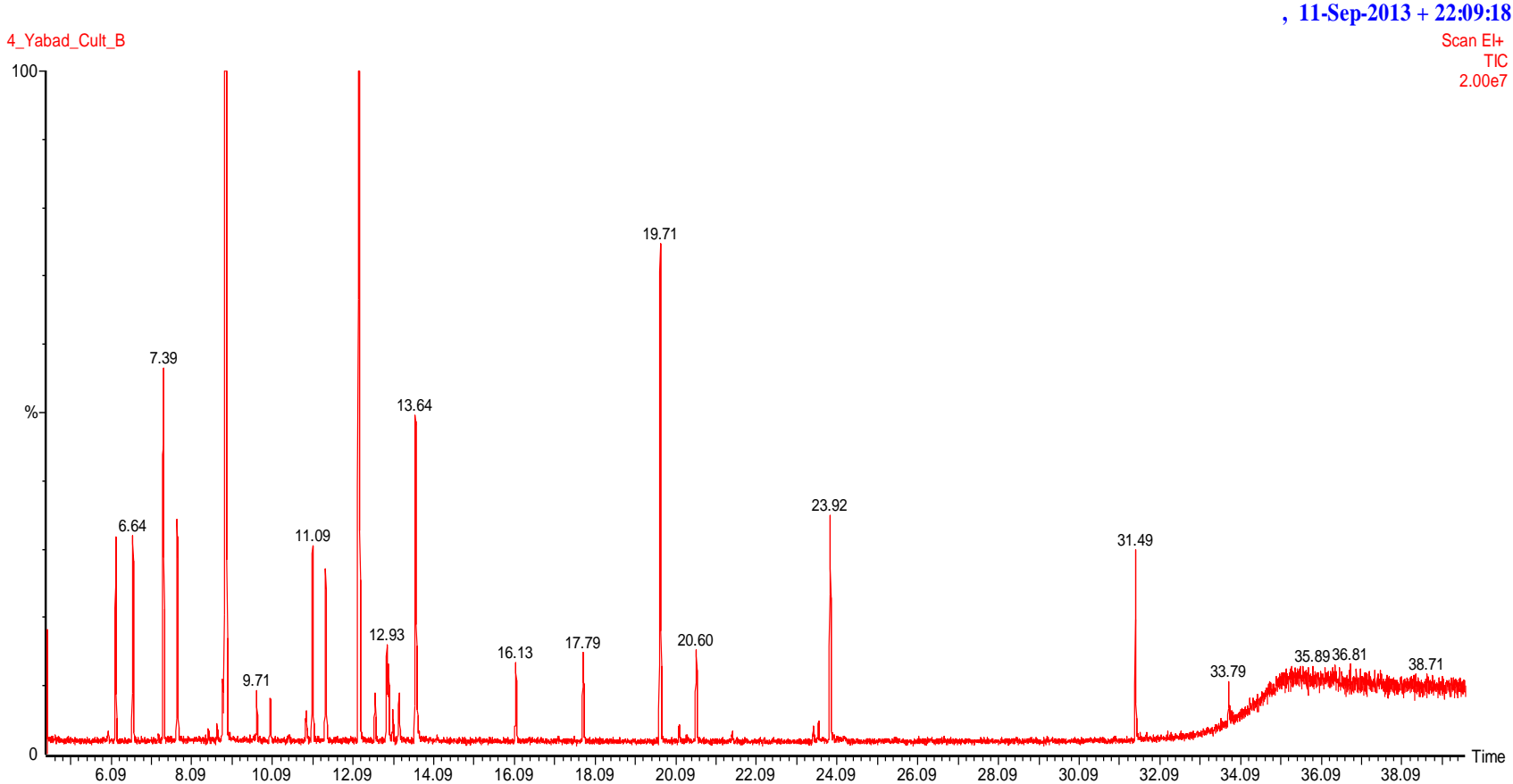

Fig. 1: TIC GC-MS of cultivated S. palaestina essential oil collected from Ya'bad, Jenin. 


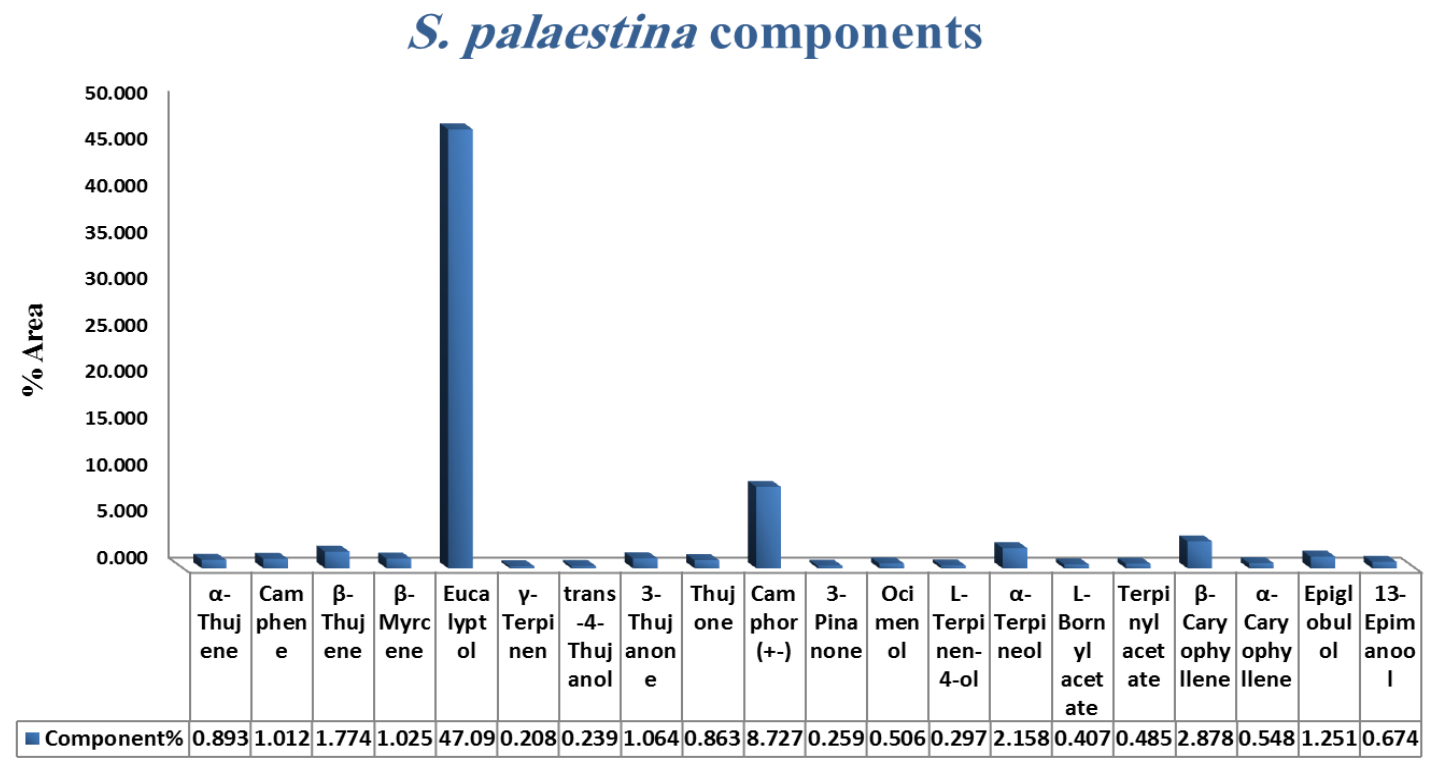

Fig. 2: Histogram of the percentage of essential oil components of S. palaestina from Ya'bad, Jenin as determined by GC-MS.

Antioxidant activity of $S$. palaestina oil after $30 \mathrm{~min}$.

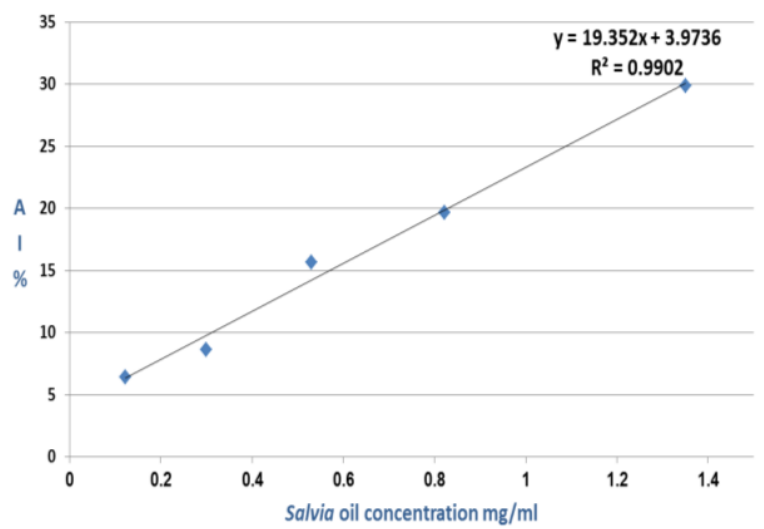

Antioxidant activity of BHT after $30 \mathrm{~min}$.

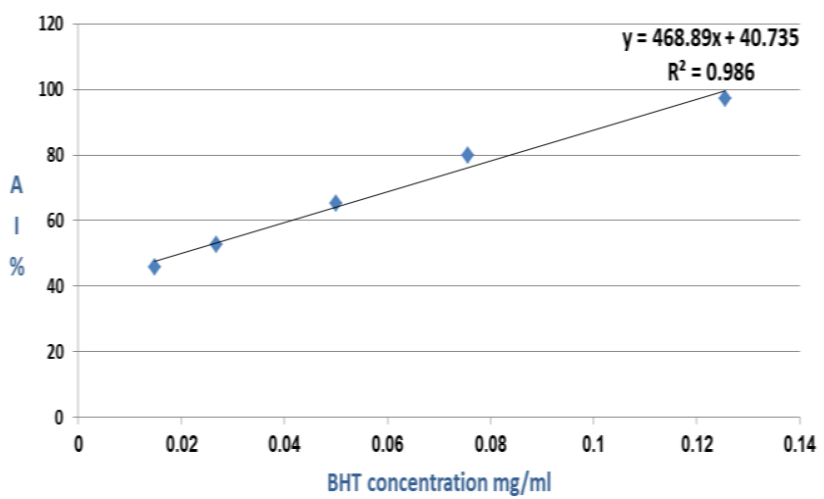

Fig. 3: (A) Antioxidant activity of Palestinian S. palaestina oil, (B) antioxidant activity of the BHT after 30 mins.

\section{Antioxidant activity of $S$. palaestina}

All $\mathrm{A}_{\mathrm{i}} \%$ values were plotted against their corresponding concentrations for both $S$. palaestina oil and the positive control in three time intervals of 30,60 and 90 minutes respectively (Figures 3-5). Linear relation between concentration and antioxidant activity was observed. The inhibition concentration $\left(\mathrm{IC}_{50}\right)$ was calculated and it was $2.333 \mathrm{mg} / \mathrm{ml}$ for the oil and $0.02 \mathrm{mg} / \mathrm{ml}$ for BHT, which means that the antioxidant activity of the oil is less than that of the positive control. $\mathrm{IC}_{50}$ after $60 \mathrm{~min}$. was calculated and it was $1.852 \mathrm{mg} / \mathrm{ml}$ for $S$. palaestina oil, while it was 0.004 $\mathrm{mg} / \mathrm{ml}$ for BHT, which means that the activity of the oil is still less than that of the positive control. $\mathrm{IC}_{50}$ for $S$. palaestina oil was $1.585 \mathrm{mg} / \mathrm{ml}$, while it was excluded for BHT because of unharmonized values. $\mathrm{IC}_{50}$ values for both sample and positive control were represented in figure 6 . It is obvious from the histogram that $S$. palaestina oil has less antioxidant activity than that of the positive control; hence, the activity of $2.333 \mathrm{mg} / \mathrm{ml}$ of the oil is equal to $20 \mu \mathrm{g} / \mathrm{ml}$ of BHT after $30 \mathrm{~min}$. Furthermore, after $60 \mathrm{~min} .1 .852 \mathrm{mg} / \mathrm{ml}$ will give the same antioxidant activity as that of $4 \mu \mathrm{g} / \mathrm{ml}$ of $\mathrm{BHT}$. Within the tested range of concentrations, free radical scavenging capacity of the tested $S$. palaestina oils increased in a concentration dependent manner.

DPPH scavenging activities increased significantly with increasing the concentration from 0.122 to $1.35 \mathrm{mg} / \mathrm{ml}$ of S. palaestina essential oil.

In addition, the activity of the oil increased with time, thus to achieve a good antioxidant activity, sufficient time is required. The activity was mainly attributed to the major effective components i.e., oxygenated terpenes such as eucalyptol and camphor. Preliminary GC-MS screening indicated the presence of these compounds in S. palaestina's from different other locations in the Mediterranean region, which are considered as free radical scavengers (Al-Qudah et al., 2014, Gürsoy et al., 2012, Tenore et al., 2011). 
Antioxidant activity of $S$. palaestina oil after $60 \mathrm{~min}$.

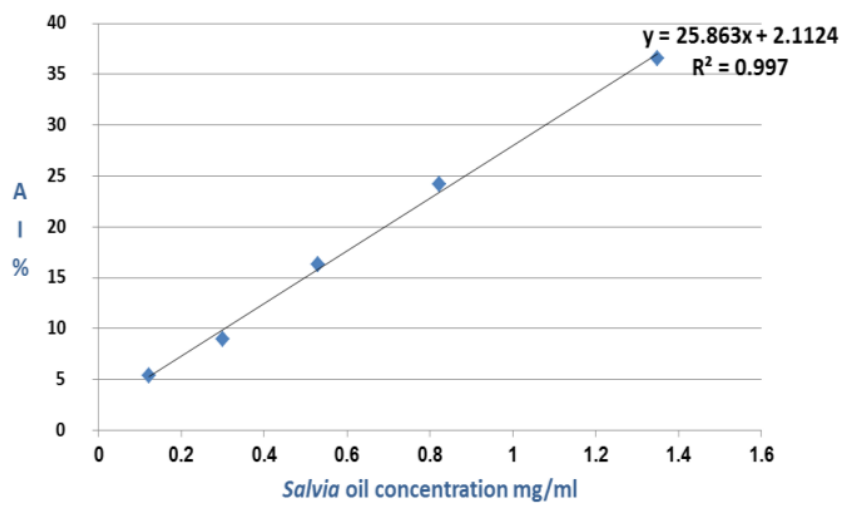

Antioxidant activity of BHT after 60min.

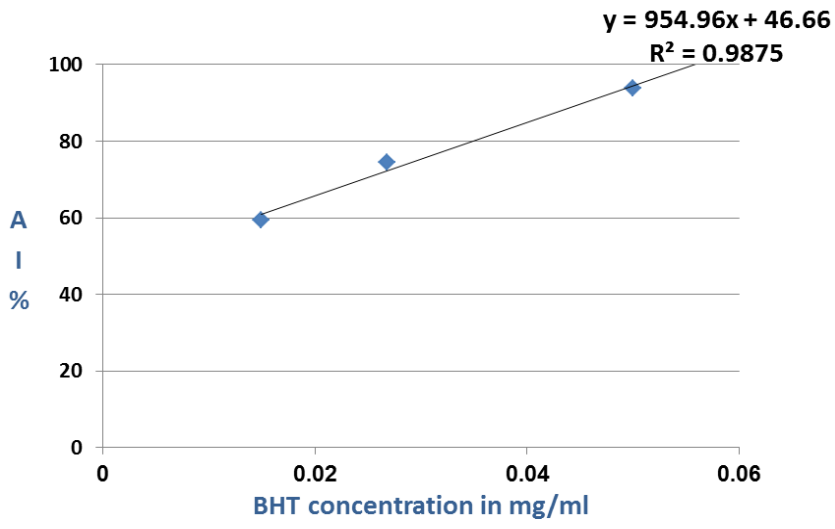

Fig. 4: (A) Antioxidant activity of the S. palaestina oil, (B) antioxidant activity of the BHT after 60 mins.

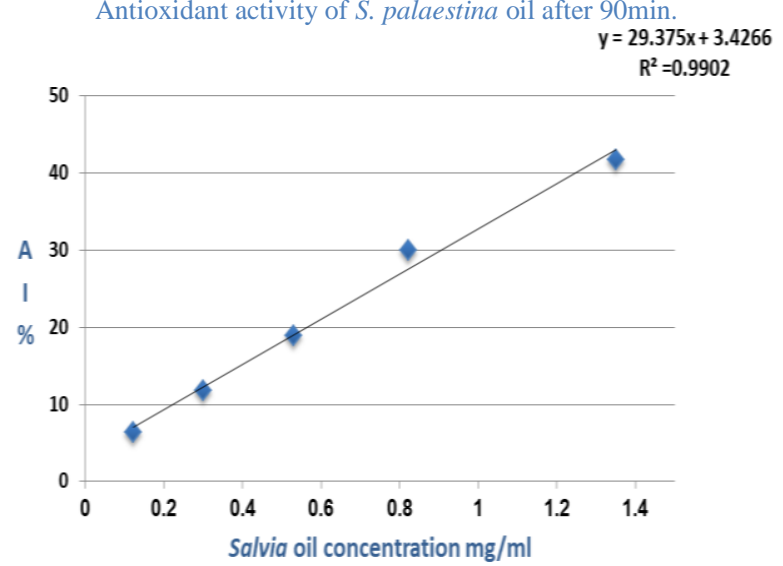

Fig. 5: Antioxidant activity of S. palaestina oil after $90 \mathrm{~min}$

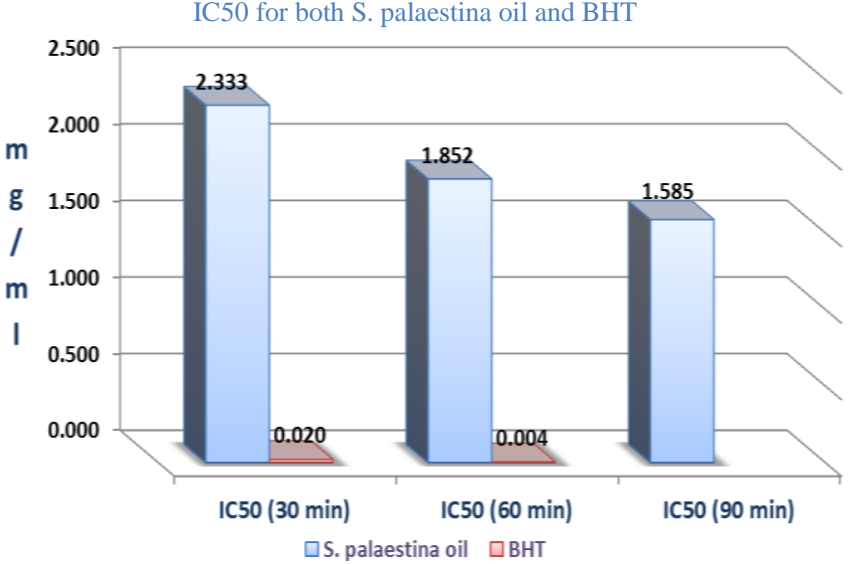

Fig. 6: $\mathrm{IC}_{50}$ for both $S$. palaestina oil and the positive control

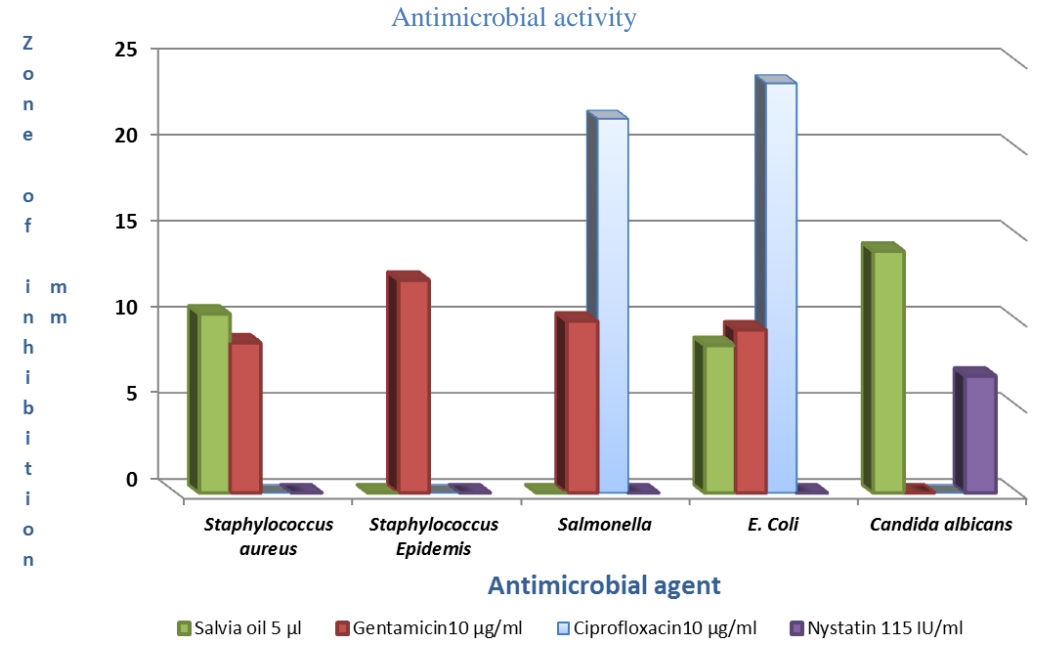

Fig. 7: Antimicrobial activity of cultivated S. palaestina oil.

Although native $S$. palaestina (at vegetative stage) does not have the antioxidant activity as that of BHT but currently, there is considerable interest in new natural antioxidants to replace the synthetic especially in food and cosmetic products. Several studies were conducted on the available synthetic antioxidants BHT and BHA to evaluate the safety of both substances. It turned out that long exposure might cause thyroid, liver, kidney dysfunctions and might also affect the lung function and blood coagulation. Moreover, it was suggested that high doses of BHT might mimic estrogen, the main female sex hormone, causing reproductive system dysfunctions (Clapp et al., 1979, Kahl and Kappus, 1993). 


\section{Antimicrobial activity}

The antimicrobial activity of $5 \mu \mathrm{l}$ of $S$. palaestina essential oil was examined on gram positive bacteria (Staphylococcus aureus, Staphylococcus epidermis), gram negative bacteria (Salmonella typhimurium, E. coli) and fungus (Candida albicans) in the presence of positive control (gentamicin, ciprofloxacin and nystatin) by using disc diffusion method. The zones of inhibition were measured and the average results of zones of inhibition were summarized in Table 1. Comparison between antimicrobial activities is illustrated in Figure 7. It is clear that $5 \mu 1$ of $S$. palaestina essential oil exhibits notable antimicrobial activity against some gram positive bacteria (Staphylococcus aureus) and some gram negative bacteria (E. coli). This observed activity is superior to gentamicin in the case of Staphylococcus aureus and almost nearly the same as that of gentamicin in the case of E. coli. Moreover, this small volume of $S$. palaestina oil was two times more effective than nystatin in the case of Candida albicans. Conversely, this volume of tested oil does not exhibit any activity neither on Staphylococcus epidermis nor on Salmonella typhimurium. Regardless of effectiveness, the usage of gentamicin is restricted by its toxicity, which includes ototoxicity and nephrotoxicity. This reported toxicity remains a major problem in clinical use (Andreu et al., 1985, Dulon et al., 1988).

Table 1: The antimicrobial activity of S. palaestina essential oil (average inhibition zone in $(\mathrm{mm})$ ).

\begin{tabular}{|c|c|c|c|c|c|}
\hline & 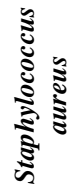 & 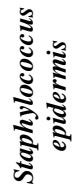 & 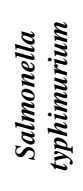 & $\underset{0}{\tilde{8}}$ & 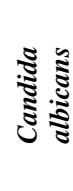 \\
\hline S.palaestina oil $5 \mu 1$ & 10.39 & ND & ND & 8.57 & 14.04 \\
\hline Gentamicin $10 \mu \mathrm{g} / \mathrm{ml}$ & 8.72 & 12.36 & 9.98 & 9.47 & NT** \\
\hline Ciprofloxacin $10 \mu \mathrm{g} / \mathrm{ml}$ & NT* & NT & 21.73 & 23.79 & NT \\
\hline Nystatin $115 \mathrm{IU} / \mathrm{ml}$ & NT & NT & NT & NT & 6.79 \\
\hline Blank & ND & ND & ND & ND & ND \\
\hline
\end{tabular}

*ND: Not detected, **NT: Not tested

It is well known that nystatin resistance was reported after gradual exposure, seven isolates of Candida species became resistant (Athar and Winner, 1971). In addition, it has no appreciable activity against bacteria, protozoa, or viruses. It is contraindicated in patients with history of hypersensitivity which might include the following side effects; tachycardia, bronchospasm, facial swelling, sever skin reactions which all required immediate emergency admission. Minor adverse reactions might include diarrhea (in some cases bloody diarrhea), vomiting, nausea, rashes, urticaria, Stevens-Johnson syndrome, and nonspecific myalgia (available at http://www.drugs.com). Although ciprofloxacin's antimicrobial activity is greater than that of $5 \mu 1$ of the oil against tested organisms, but it's contraindicated in ages less than 18 years and its adverse reactions might be very severe such as tendon rupture which was reported recently in a number of cases. Achilles tendon rupture has been reported to the FDA in 25 cases. Some ruptures have also occurred in hands and shoulder (available at http://www.drugs.com). In general, the essential oils are hydrophobic in nature, and it was proposed that the cell membrane is the primary target of their antimicrobial action. S. palaestina essential oil seems to accumulate in the cell membrane causing leakage of enzymes, ions and metabolites (Inoue et al., 2004). In the case of gram negative bacteria there might be resistance to the essential oil due to the additional outer membrane of their cell wall, which acts as a barrier to many substances including antibiotics (Palombo and Semple, 2001). Furthermore, the antimicrobial activity of S. palaestina essential oil on Candida is mainly due to the antimicrobial constituents especially eucalyptol, which are capable of changing the structure and moisture of mucous membranes of fungal cells, interfering with the respiratory processes, and thus eliminating the pathogen (Chen et al., 2013). It was suggested that the antimicrobial activity of $S$. palaestina oil from other locations in the Mediterranean was probably due to its constituents (thujone, eucalyptol, camphor, camphene and caryophylline). However, when comparing the antimicrobial activity of each constituent with the antimicrobial activity of the whole oil, the oil activity was superior. This indicates that their antimicrobial effect probably involves some type of synergism between many constituents (Fraternale et al., 2012, Mitić-Ćulafić et al., 2005). Thus, the overall therapeutic effect of $S$. palaestina oil could be attributed to the synergistic interactions of individual components and to the anti-inflammatory approved effect of this oil, which can lead to easier passage of the essential oils through mucous membrane.

\section{CONCLUSION}

The antioxidant activity results revealed that the activity of S. palaestina oil is less than that of the positive control (BHT). Nonetheless, it increased with time thus special sustained release formulations might be helpful. Moreover, $S$. palaestina oil revealed antimicrobial activity against both bacteria and fungi. It was superior to some available antibiotics in certain cases. Small volume of $5 \mu \mathrm{l}$ of essential oil exhibits notable antimicrobial activity against some gram positive bacteria (Staphylococcus aureus) and some gram negative bacteria (E. coli). The observed activity of essential oil (100\%) was superior to gentamicin (10 $\mu \mathrm{l} / \mathrm{ml}$ ) in case of Staphylococcus aureus and almost the same in case of $E$. coli. Furthermore, this small volume of oil (100\%) was two times more effective than nystatin $(115 \mathrm{IU} / \mathrm{ml})$ in case of Candida albicans. This promising result is important due to the increasing resistance against available antimicrobial agents in addition to its known toxicity.

\section{ACKNOWLEDGEMENT}

We would like to thank the Central Public Health Laboratory CPHL staff, Ministry of Health in Ramallah for providing the GC-MS instrument for the analysis. Special thanks to Dr. Asad Ramlawi, Deputy Minister, Ministry of Health for his continuous support. Thanks are extended to Mr. Ibrahim Salem for facilitating this research at the Ministry of Health in Ramallah. 


\section{REFERENCES}

Al-Qudah M. A., Al-Jaber H. I., Abu Zarga M. H., Abu Orabi S. T. Flavonoid and phenolic compounds from Salvia palaestina L. growing wild in Jordan and their antioxidant activities. Phytochemistry, 2014; 99, $115-120$.

Andreu J., Bodet B., Garand G., Dabo B., Leroy G. Ototoxicity and nephrotoxicity of gentamicin and tobramycin. Cah Anesthesiol, 1985; 33(6), 515-521.

Aruoma O. I. Nutrition and health aspects of free radicals and antioxidants. Food Chem Toxicol, 1994; 32(7), 671-683.

Athar M. A., Winner H. I. The development of resistance by Candida species to polyene antibiotics in vitro. J Med Microbiol, 1971; 4(4), 505-517.

Bohm H., Boeing H., Hempel J., Raab B., Kroke A. Flavonols, flavone and anthocyanins as natural antioxidants of food and their possible role in the prevention of chronic diseases. Z Ernahrungswiss, 1998; 37(2), 147-163.

Brand-Williams W., Cuvelier M. E., Berset C. Use of a free radical method to evaluate antioxidant activity. LWT-Food Science and Technology, 1995; 28(1), 25-30.

Briskin D. P. Medicinal plants and phytomedicines. Linking plant biochemistry and physiology to human health. Plant Physiol, 2000; 124(2), 507-514.

Chen Y., Zeng H., Tian J., Ban X., Ma B., Wang Y. Antifungal mechanism of essential oil from Anethum graveolens seeds against Candida albicans. J Med Microbiol, 2013; 62(Pt 8), 1175-1183.

Clapp N. K., Satterfield L. C., Bowles N. D. Effects of the antioxidant butylated hydroxytoluene (BHT) on mortality in BALB/c mice. J Gerontol, 1979; 34(4), 497-501.

Devasagayam T. P., Tilak J. C., Boloor K. K., Sane K. S., Ghaskadbi S. S., Lele R. D. Free radicals and antioxidants in human health: current status and future prospects. J Assoc Physicians India, 2004; 52, 794-804.

Dulon D., Aurousseau C., Erre J. P., Aran J. M. Relationship between the nephrotoxicity and ototoxicity induced by gentamicin in the guinea pig. Acta Otolaryngol, 1988; 106(3-4), 219-225.

Emerit J., Michelson A. M. Free radicals in medicine and biology. Sem Hop, 1982; 58(45), 2670-2675.

Enwonwu C. O., Salako N. The periodontal disease-systemic health-infectious disease axis in developing countries. Periodontol 2000, 2012; 60 (1), 64-77.

Fraternale D., Flamini G., Bisio A., Albertini M. C., Ricci D. Chemical composition and antimicrobial activity of Salvia $\mathrm{x}$ jamensis essential oil. Nat Prod Commun, 2012; 7(9), 1237-1240.

Gürsoy N., Tepe B., Akpulat H. A. Chemical Composition and Antioxidant Activity of the Essential Oils of Salvia palaestina (Bentham) and S. ceratophylla (L.). Rec. Nat. Prod, 2012; 6:3, 278-287.

Gutteridge J. M., Halliwell B. Comments on review of Free Radicals in Biology and Medicine, second edition, by Barry Halliwell and John M. C. Gutteridge. Free Radic Biol Med, 1992; 12(1), 93-95.

Halliwell B. Role of free radicals in the neurodegenerative diseases: therapeutic implications for antioxidant treatment. Drugs Aging, 2001; 18(9), 685-716.

Inoue Y., Shiraishi A., Hada T., Hirose K., Hamashima H., Shimada J. The antibacterial effects of terpene alcohols on Staphylococcus aureus and their mode of action. FEMS Microbiol Lett, 2004; 237(2), 325331.
Kahl R., Kappus H. Toxicology of the synthetic antioxidants BHA and BHT in comparison with the natural antioxidant vitamin E. Z Lebensm Unters Forsch, 1993; 196(4), 329-338.

Kamatou G. P., Makunga N. P., Ramogola W. P., Viljoen A. M. South African Salvia species: a review of biological activities and phytochemistry. J Ethnopharmacol, 2008; 119(3), 664-672.

Liao K., Yin M. Individual and combined antioxidant effects of seven phenolic agents in human erythrocyte membrane ghosts and phosphatidylcholine liposome systems: importance of the partition coefficient. J Agric Food Chem, 2000; 48(6), 2266-2270.

Lobo V., Patil A., Phatak A., Chandra N. Free radicals, antioxidants and functional foods: Impact on human health. Pharmacogn Rev, 2010; 4(8), 118-126.

Miguel G., Cruz C., Faleiro M. L., Simoes M. T., Figueiredo A. C., Barroso J. G., Pedro L. G. Salvia officinalis L. essential oils: effect of hydrodistillation time on the chemical composition, antioxidant and antimicrobial activities. Nat Prod Res, 2011; 25(5), 526-541

Mitić -Ćulafić, D., Vuković -Gačić, B., Knežević -Vukčević J., Stanković S., and Simić, D. Comparative study on the antibacterial activity of volatiles from Sage (Salvia officinalis L.). Arch. Biol. Science, 2005; 57(3), 173-178.

Palombo E. A., Semple S. J. Antibacterial activity of Australian plant extracts against methicillin-resistant Staphylococcus aureus (MRSA) and vancomycin-resistant enterococci (VRE). J Basic Microbiol, 2002; 42(6), 444-448.

Palombo E. A., Semple S. J. Antibacterial activity of traditional Australian medicinal plants. J Ethnopharmacol, 2001; 77(2-3), 151-157.

Papas A. M. Diet and antioxidant status. Food Chem Toxicol, 1999; 37(9-10), 999-1007.

Sanches-Silva A., Costa D., Albuquerque T. G., Buonocore G. G., Ramos F., Castilho M. C., Costa H. S. Trends in the use of natural antioxidants in active food packaging: a review. Food Addit Contam Part A Chem Anal Control Expo Risk Assess, 2014; 31(3), 374-395.

Sonboli A., Babakhani B., Mehrabian A. R. Antimicrobial activity of six constituents of essential oil from Salvia. Z Naturforsch C, 2006; 61(3-4), 160-164.

Stary F. 1996. The natural guide to medicinal herbs and plants, Barnes \& Noble Books, New York by arrangement with Aventium Publishers, Prage, Czech Republic.

Tenore G. C., Ciampaglia R., Arnold N. A., Piozzi F., Napolitano F., Rigano D., Senatore F. Antimicrobial and antioxidant properties of the essential oil of Salvia lanigera from Cyprus. Food Chem Toxicol, 2011; 49(1), 238-243.

Valko M., Rhodes C. J., Moncol J., Izakovic M., Mazur M. Free radicals, metals and antioxidants in oxidative stress-induced cancer. Chem Biol Interact, 2006; 160(1), 1-40.

\section{How to cite this article:}

Sabbobeh R, Hejaz H, Jahajha A, Al-Akhras S, Al-Jaas H. and Abu-Lafi S. Antioxidant an Antimicrobial Activities of the Leaf Extract of Salvia palaestina. J App Pharm Sci, 2016; 6 (01): 076082 . 